\title{
An Experimental Study with Objectives Functions for Portfolio Optimization Problem
}

\author{
Darsha Panwar
}

\begin{abstract}
This paper presents an experimental study with the objective's functions of a portfolio optimization problem. This study is done by three optimization problems with a different number of objectives. A hybrid approach has been adopted for this which is a combination of a few methods, such as investor topology, cluster analysis, analytical hierarchy process (AHP), and optimization techniques. Teaching-learning-based optimization (TLBO), biogeography-based optimization (BBO), and fuzzy multi-objective linear programming (FMOLP) are compared in this paper for portfolio optimization. From this research, the conclusion comes that there should not be more options in the objective functions, otherwise the motive of the portfolio becomes misleading, but many more parameters can be used for stock valuation.
\end{abstract}

Keywords - Teaching-learning-based algorithm; biogeography-based algorithm; fuzzy multi-objective linear programming; Portfolio optimization.

\section{INTRODUCTION}

The selection of stocks is a challenging task for investors and finance researchers because of the uncertainty of return. The investment of stock does not guarantee since the decision requires to be made today with missing information about future prices. In portfolio selection, the aim is to obtain a proper proportion of assets for getting maximum profit and least risk.

The portfolio selection problem was initially introduced by Professor Harry Markowitz [1] and he was awarded the Nobel Prize in Economics in 1990 for his great contribution to the portfolio selection problem. He introduced the Markowitz model or mean-variance (MV) model in which return is calculated as the mean and risk as a variance. He gave the concept that holding two or more assets are less risky than holding one asset, and this has become a foundation of modern portfolio theory.

Konno and Yamazaki [2] introduced an improved and simplified version of Markowitz's Model both computationally and theoretically where risk is calculated as mean absolute deviation (MAD) instead of variance.

Manuscript revised on January 05, 2022 and published on January 10, 2022

Darsha Panwar, Mathematics Department, SISTEC Ratibad, Bhopal, India. Email.ID: panwar.darsha@gmail.com
Speranza [3] presented a linear programming model related to portfolio selection and used semi absolute deviation to measure risk.

Konno and Suzuki [4] proposed a mean-variance skewness model for portfolio optimization which is the extended version of the standard mean-variance model. For this, the skewness of the rate of return and the third-order derivative of the utility function is the significant parameters. They conclude that the third-order derivative term can't be neglected and allows us to maximize it.

T. Joro and P. Na [5] developed a performance evaluation for portfolio efficiency on mean-variance skewness by employing Data Envelopment analysis. They suggested that this framework is more efficient than the mean-variance model. Although there is no proper technique to test the efficiency of this framework. Jana et. al., [6] presented a multi-objective nonlinear programming approach with transaction cost, assuming risk, return, liquidity and entropy as objective functions. The proposed model is solved by the fuzzy nonlinear programming technique. Gupta et. al. [7] presented a detailed overview of portfolio optimization. They started with the Markowitz model and then discuss the extended version of the Markowitz model based on different formats of risk calculating functions namely the semi-variance model, absolute deviation model, and semi absolute deviation model. After that, they discussed their portfolio selection model and concluded that portfolio optimization is also affected by investors' behavior. Cluster analysis and ranking of assets are also important features for selecting the assets. Mehlawat [8] presented a detailed computation procedure of AHP and determined the suitability performance score of the assets with the help of the AHP model. He applied the FMCDM technique to obtain optimal portfolios. Solimanpur et. al., [9] presented a multi-objective genetic algorithm and AHP with three-level hierarchies for portfolio optimization.

From the previous work done the conclusion comes that portfolio optimization is done by different approaches and techniques with different objective functions but there is no experimental study for the objective function, while it is important and always needed revision.

This article presented a portfolio selection problem which is a multi-objective linear programming problem as well as an experiment within objective functions. Three hybrid approaches are proposed for portfolio selection using investor behavior, cluster analysis, AHP, and optimization technique. The data for an experimental and numerical study has been taken from the Bombay Stock Exchange from 
February'2016 to January'2017 which is discussed in [10, $11] \&[20]$. The genetic algorithm and fuzzy decision theory are applied for portfolio selection. LINGO, MATLAB, and RAPID-MINOR are used for solving the multi-objective problem, and cluster analysis, respectively.

\section{Methodology}

The following methodology is accepted for this experimental study.

\section{A. Investor's Topology}

The role of the Investor's behavior [12] is significant in picking the stocks as all the investors have a different strategy for it. The factors under which investment is affected are, the economic condition, information about investment, the purpose of investing, and there are also social and personal factors. The key elements such as different ages, income, and savings have become the deciding factors for investment.

\section{B. Cluster Analysis}

The prepared data of 146 stocks are clustered using the EM algorithm [13], and the x-means algorithm [14]. The EM algorithm is a distribution model and maintains multivariate normal distribution. It calculates the weighted distance. In the $\mathrm{x}$-means algorithm, the number of clusters is decided by itself. The initial distribution of the centroid is to start with just one unit and then increase it if required. The statistical model Bayesian Information Criteria is applied for data distribution when a cluster is divided into two sub-clusters. The selected 146 stocks are divided into three clusters as the investors focus only on the three points, namely, return, risk, and liquidity. The result of cluster analysis for both the techniques are given in $[10,11]$.

According to the investor's survey stocks are divided into the following three clusters:

- Cluster 1 (liquid stocks): Investors who are looking for a secure investment.

- Cluster 2 (low-risk stocks): Investors who are looking for a less risky investment.

- Cluster 3 (high return stocks): Investors who are looking for a high-profit investment.

\section{AHP}

Thomas L. Saaty addressed AHP, which is a multi-criteria decision-making (MCDM) tool in the 1970s [15]. AHP is a very important tool where many alternative needs are to be evaluated. AHP is used for the evaluation of assets as per the investor's preference. Ranking of assets can be done with the help of AHP. Hierarchy structure, priority analysis, and consistency verification are the three key steps of AHP.

\section{Problem I}

A portfolio selection problem with five objectives is solved in Problem I using cluster analysis using the EM technique, AHP technique, and optimization technique. The teaching-learning-based optimization technique is applied for the portfolio selection problem. The five objectives objective functions for portfolio selection problems are return, risk, liquidity, dividend, and AHP weight.

The TLBO algorithm introduced by Rao et. al., in 2011 [16, 17] is inspired by the teaching-learning process. TLBO produced improved results as compared to other evolutionary computation techniques like PSO, differential evolution, and the artificial bee colony. The highest mean value learner is known as a teacher and the rest of the population is known as a learner. These learners are trained by the teacher so that they have better results.

The complete methodology and data analysis are given in [10].

\section{Problem II}

A portfolio selection problem with seven objective functions is solved in Problem II using a hybrid approach that combines investor topology, cluster analysis using the $\mathrm{X}$-means algorithm, AHP, and optimization technique. The FMOLP is applied for solving optimization problems with seven objective functions. The seven objective functions for the portfolio selection problem are return, risk, AHP weight, RSI, CV, EY, and PEG ratio.

The FMOLP [18] technique is frequently used in a portfolio selection problem. With the help of a membership function, a multi-objective function can be converted into a single objective function.

The complete methodology and data analysis are given in [11].

\section{Problem III}

A portfolio selection problem with eight objective functions is solved in Problem III using a hybrid approach that combines investor topology, cluster analysis using the $\mathrm{x}$-means algorithm, AHP, and optimization technique. For stock selection and optimization, BBO is used. BBO is a population-based algorithm introduced by Dan Simon in 2008 [19]. It is an evolutionary algorithm based on the concept of migration and mutation. The migration operator has immigration and emigration probability. In BBO each set has its habitat suitability index (HSI) (fitness value), which shows the efficiency of the solution. Each habitat depends on variables called suitability index variables (SIVs). A high HSI is a good indication of a maximization problem and a low HSI represents a good operator for minimization. High HSI shows a habitat contains many species and low HSI shows that a habitat contains few species.

The complete methodology and data analysis are given in [20].

\section{EXPERIMENTAL STUDY}

The risk/return ratio shows the risk-return trade-off and it is a key factor that helps in investment, and for those who have a little bit of knowledge about stock selection. Investors who are not interested in taking higher risks would like to go with a lower risk/return ratio. In the same way, investors whose risk tolerance level is high would like to invest with a higher risk/return ratio. 
Table 6.8. Risk/return ratio for all three clusters with respect to each technique.

\begin{tabular}{|l|l|l|l|}
\hline \multicolumn{4}{|l|}{ Risk/return ratio } \\
\hline Technique & Cluster 1 & Cluster 2 & Cluster 3 \\
\hline Problem I & 0.7616 & 0.7877 & 0.7275 \\
\hline Problem II & 0.7014 & 0.6140 & 0.8146 \\
\hline Problem III & 0.8450 & 0.9069 & 0.6744 \\
\hline
\end{tabular}

From the above results, Problem I has 5, Problem II has 7, and Problem III has 8 objective functions. The Problem III risk/return ratio is the highest and from the investor's topology, the investors are risk-averse. If objective functions are less the optimization technique focused very well. We conclude that the basic objective function should be return, risk, liquidity and there should not be more options in the objective functions, otherwise, the motive of the portfolio becomes misleading.

\section{Conclusion}

This research paper includes three hybrid approaches are proposed for portfolio selection using investor behavior, cluster analysis, AHP, and three optimization technique. After experimentation, it was concluded that by taking more objective functions the purpose of portfolio optimization does not serve any objective, even though more parameters can be taken for stock valuation.

\section{CONFLICT OF INTEREST}

"The authors declare no conflict of interest".

\section{REFERENCES}

[1] H. Markowitz, "Portfolio Selection," The journal of finance, vol. 7, no. 1, pp. 77-91, 1952.

[2] H. Konno, and H. Yamazaki, "Mean-absolute deviation portfolio optimization model and its applications to Tokyo stock market," Management Science, vol. 37, no. 5, pp. 519-531, 1991.

[3] M. G. Speranza, Linear programming models for portfolio optimization, 1993

[4] H. Konno, and K.-i. Suzuki, "A mean-variance-skewness portfolio optimization model," Journal of the Operations Research Society of Japan, vol. 38, no. 2, pp. 173-187, 1995.

\section{AUTHORS PROFILE}

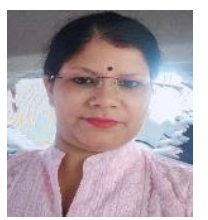

Darsha Panwar, awarded by Doctor of Philosophy in November'2020 with Financial Mathematics from Maulana Azad National Institute of Technology, Bhopal
[5] T. Joro, and P. Na, "Portfolio performance evaluation in a mean-variance-skewness framework," European Journal of Operational Research, vol. 175, no. 1, pp. 446-461, 2006.

[6] P. Jana, T. Roy, and S. Mazumder, "Multi-objective possibilistic model for portfolio selection with transaction cost," Journal of Computational and Applied Mathematics, vol. 228, no. 1, pp. 188-196, 2009.

[7] P. Gupta, M. K. Mehlawat, M. Inuiguchi, and S. Chandra, Fuzzy portfolio optimization: advances in hybrid multi-criteria methodologies: Springer, 2014.

[8] M. K. Mehlawat, "Behavioral optimization models for multicriteria portfolio selection," Yugoslav Journal of Operations Research, vol. 23, no. 2, 2016.

[9] M. Solimanpur, G. Mansourfar, and F. Ghayour, "Optimum portfolio selection using a hybrid genetic algorithm and analytic hierarchy process," Studies in Economics and Finance, vol. 32, no. 3, pp. 379-394, 2015.

[10] D. Panwar, M. Jha, and N. Srivastava, "Stock selection and portfolio optimization using a teaching-learning-based algorithm."

[11] D. Panwar, M. Jha, and N. Srivastava, "Optimization of Risk and Return Using Fuzzy Multiobjective Linear Programming," Advances in Fuzzy Systems, vol. 2018, 2018.

[12] M. Shafi, "Determinants influencing individual investor behavior in the stock market: a cross country research survey," Nigerian Chapter of Arabian Journal of Business and Management Review, vol. 62, no. 1100, pp. 1-12, 2014.

[13] M. R. Gupta, and Y. Chen, "Theory and use of the EM algorithm," Foundations and Trends ${ }^{\circledR}$ in Signal Processing, vol. 4, no. 3, pp. 223-296, 2011.

[14] D. Pelleg, and A. W. Moore, "X-means: extending k-means with efficient estimation of the number of clusters." pp. 727-734.

[15] T. L. Saaty, "Axiomatic foundation of the analytic hierarchy process," Management Science, vol. 32, no. 7, pp. 841-855, 1986.

[16] R. V. Rao, V. J. Savsani, and D. Vakharia, "Teaching-learning-based optimization: a novel method for constrained mechanical design optimization problems," Computer-Aided Design, vol. 43, no. 3, pp. 303-315, 2011

[17] R. Rao and V. Patel, "An elitist teaching-learning-based optimization algorithm for solving complex constrained optimization problems," International Journal of Industrial Engineering Computations, vol. 3, no. 4, pp. 535-560, 2012.

[18] S. Bharati, and S. Singh, "Solving multi-objective linear programming problems using intuitionistic fuzzy optimization method: a comparative study," International Journal of Modeling and Optimization, vol. 4, no. 1, pp. 10, 2014.

[19] D. Simon, "Biogeography-based optimization," IEEE transactions on evolutionary computation, vol. 12, no. 6, pp. 702-713, 2008.

[20] D. Panwar, M. Jha and N. Srivastava, "Portfolio selection and post optimality test using goal programming", International Journal of Engineering and Technology, 7 (3.27) (2018) 481-487.

and have 5 publications in reputed various Scopus Indexed Journal also published 3-Patents with IPR, 1- Australian patent received a grant and published one book chapter. 